volume is given family status, following Dahl, the practice followed in the recent Ray Society monograph on "British Spiders" by G. H. Locket and A. F. Millidge is to rank it as a sub-family, which together with the larger Erigoninae form the Linyphiidae. In German literature the Erigoninae of Locket and Millidge is ranked as a family under the name Micryphantidae.

Whether regarded as one or two families, this large and complex group of spiders has for long been very inadequately monographed in European faunas. The only modern work is by the above British authors, so that Dr. Wiehle's work is particularly welcome. Wiehle follows Locket and Millidge in the features which separate the two main groups, but he points out that there are several transitional genera so that separation cannot be complete. He believes that the Linyphiids evolved from the Micryphantids (Erigonids) and mentions various biological distinctions between the two groups, for example, broad divisions of habitat preferenda and web types.

As in previous monographs by Dr. Wiehle, there are many large and clearly drawn illustrations of structural features. He places considerable emphasis on the form of the vulva, which he says should be as well understood by the student as the epigyne. The females of some closely related species can only be distinguished by examination of the vulva.

A key is provided for the six divisions recognized by Wiehle in the family and also for the genera and species. In general the arrangement of genera follows closely that of Locket and Millidge, but there has been some generic splitting. The species in the genus Linyphia of the British monograph are to be found in three genera called by Wiehle Prolinyphia, Linyphia and Microlinyphia.

Dr. Wiehle's work will undoubtedly be widely used by British araneologists and serious consideration given to his new ideas on the taxonomy of the group.

There is a genus and species index and references to the literature consulted precede his general introduction. ERIC DUFFey

\section{ECOLOGY OF FUNGUS-HOST RELATIONSHIP IN SOIL}

Biology of Root-Infecting Fungi

By Dr. S. D. Garrett. Pp. xi +293 . (Cambridge : At the University Press, 1956.) 30s, net.

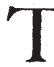
$\mathrm{HE}$ investigation of root-infecting fungi has proved extremely difficult because the roots are in the soil, which is a complex ecological association in which not only the pathogen but also a great many other micro-organisms are in precarious equilibrium. Dr. Garrett points out that the study of root-infecting fungi has passed through a number of phases; the etiological phase when research was directed to proving that certain fungi were causal organisms in specific diseases; the environmental phase when research was concerned largely with the effect of the physical environment on disease development ; and finally the present phase in which root disease is studied as an aspect of microbial ecology. It is in this last phase that Dr. Garrett has made his distinctive and distinguished contribution. This book brings together his mature views on the whole subject.
The fungal flora of the soil is reviewed from the ecological point of view and the distinction between normal soil inhabitants and soil invaders is emphasized. The significance of competition for organic substrates in soil is explained. The growth habit of parasitic soil fungi is examined and a biological classification of these, ranging from primitive unspecialized types to the symbiotic mycorrhizal fungi, is put forward. The significance of mycelial aggregation into strands and rhizomorphs is discussed with special emphasis on fungal growth on the root surface (the ectotrophic habit) prior to penetration in certain important species. A brief chapter on mycorrhiza is concerned with showing that the difference between ectotrophic mycorrhiza and root disease fungi is one of degree and not of kind. Rhizosphere and root surface floras are considered in relation to root infection.

Much attention is given to the saprophytic life of pathogens, particularly in relation to the active saprophytic colonization of substrates in the soil and to survival in dead host tissue. The biology of resting spores and sclerotia is given full consideration. There is a general discussion of the epidemiology of root diseases and the effects of the environment are stressed. Finally, the principles, both biological and economic, governing the control of root diseases are outlined.

The feature that really distinguishes this book is the successful attempt by the author to synthesize his unique first-hand experience and his vast knowledge of the literature into a coherent whole. The book is written clearly and in a vigorous style. It has a philosophic air about it which will commend it not only to mycologists with an earthy interest but also to all mycologists and, indeed, to botanists generally. It is full of suggestive ideas, many of which have a relevance far beyond the soil.

The work has been condensed from Dr. Garrett's unique knowledge. Some mycologists, not themselves working on root disease fungi, might, perhaps, have welcomed an even greater condensation so that the essential ecological and biological principles developed by the author might have shone forth with even greater brightness. But this is a small criticism. There can be no doubt that the author has contributed a book of outstanding mycological im. portance which will have a most significant bearing on future research on soil fungi. C. T. INGOLD

\section{THE NATURE OF DELUSIONS}

\section{Schizophrenia 1677}

A Psychiatric Study of an Illustrated Autobiographical Record of Demoniacal Possession. By Ida Macalpine and Richard A. Hunter. (Psychiatric Monograph Series.) Pp. ix $+197+12$ plates. (London : William Dawson and Sons, Ltd., 1956.) $130 s$.

DLUSIONS have always had a strong fascina. tion, not only for the general public to which they are inexplicable, but also to the psychiatrist who tries to unravel their nature and causation. There is an uncanny strangeness about them which arouses deep-seated horror. The apparently astute business man, the happy wife, or the successful student starts to talk and write in a way which reveals that he or she has lost touch with the real world. A belief in strange plots attributed to Freemasons, 